\title{
Monitoring Slope Condition Using UAV Technology
}

\author{
Norhayati Ngadiman*, Ibrahim Adham Badrulhissham, Mazlan Mohamad, Nurazira Azhari, \\ Masiri Kaamin, Nor Baizura Hamid
}

Department of Civil Engineering, Centre for Diploma Studies (CeDS), Universiti Tun Hussein Onn Malaysia (UTHM), Malaysia

Received July 30, 2019; Revised September 30, 2019; Accepted December 10, 2019

Copyright $\bigcirc 2019$ by authors, all rights reserved. Authors agree that this article remains permanently open access under the terms of the Creative Commons Attribution License 4.0 International License

\begin{abstract}
Slope failure is a serious geologic hazard in many countries in the world including Malaysia. In order to prevent slope failure, the hazardous symptoms can be detected early in slope monitoring process. Nowadays, slope failure symptoms monitoring has been done by human by on site observation at the slope spot and it is dangerous for the human safety. Furthermore, it takes longer time to complete the investigation and some of the data collected are inaccurate because human view is limited. Therefore, this project is to evaluate the performances of Unmanned Aerial Vehicle (UAV) to monitor the slope condition. A slope at Taman Harmoni Vista at Pagoh, Johor has been selected as a study area. The measurement of slope studied was 150 meters in length and 20 meters in height respectively. The aim of this project is to evaluate the performances of Unmanned Aerial Vehicle (UAV) to monitor the risk slope. Visual image of 3D modelling was obtained from Pix4D Mapper and Global Mapper software was used to analyze the slope failure symptoms. There are defects that have been identified from 3D modelling of the slope which is tension crack on slope and surface crack on the drainage. The use of UAV is an alternative method to obtain quality picture and 3D model for inspection of the slope. This method expected to facilitate the work of inspection slopes in addition to saving time, energy and cost as well asreducing the risk of harm.
\end{abstract}

Keywords Slope Failure, Slope Monitoring, Unmanned Aerial Vehicle (UAV)

\section{Introduction}

Landslides are usually found in the form of slope failure in a man-made slope, especially the slopes involved with cut and fill activities which often occur along highway area, residential area and urban area [1]. Slope falls, slope topples, landslides, flows and spreads of slope are types of slope failure [2]. Slope failures occur in many forms and there is a wide range in their predictability, rapidity of occurrence and movement, and ground area affected, all of which relate directly to the consequences of failure [3]. There are several types of slope failures that can occur when the shear resistance along the slip plane is exceeded. Slope falls, slope topples, landslides, flows and spreads of slope are the types of slope failure. These can be caused by excessive load imposed at the slope crest or compromised stability of the slope, and disturbed dimensions of the slope.

Monitoring of slopes is a crucial method to predict early sign of slope failure and prevent slope from collapse. Conducting a quantitative study on the unstable slope area will be able to detect any movement on the slope. Therefore, detailed orthophotos are a valuable resource for mapping and classifying morphological phenomena that occur at that point [4]. Initial information obtained will provide preliminary information on the slope and be able to detect slope stability level prior to the occurrence of slope failure [5]. Monitoring is an important element of hazard identification, hazard assessment and hazard information which can be supported by Geographical Information Systems (GIS) and related databases. Nowadays, slope analysis is done by inspector that inspecting and monitoring will climb up to the top of the slope for the purpose of taking photographs for inclusion in the work report [6]. This method needed more time to complete the observation and the data was collected not too accurately because the human errors sometimes fail to read the data correctly.

This study was conducted to determine the extent to which the use of Unmanned Aerial Vehicle (UAV) can assist in the slope monitoring process. The main objectives of this study are to produce a 3-dimensional model of the slope to determine defects that occur on the slopes. The UAV can be controlled by a safe distance from a risky slope. UAV can be manually or autonomously controlled [7]. Basically, the monitoring process can be done safely, quickly and more energy work can be saved by using this technology. The purpose of this paper was to identify the 
effectiveness of an UAV in monitoring high risk slope and analyze the probability of slope failure symptoms based on the 3D slope modelling using Pix4D Mapper and Global Mapper software. This study will help researchers and developers to maintain the slopes safety effectively.

\subsection{Slope Monitoring}

Slope is any ground in which surface forms an angle with the horizontal plane [8]. Rainfall or an earthquake can weaken slope structure thus causing slope collapses abruptly. Sudden collapse of slope may cause a great natural disaster that may result loss of life and property. The effectiveness of monitoring depends on the extent of the slope, and giving adequate warning before it failed depends also on the ability of the monitoring system to detect the warning [9]. Visual inspection of the slope often needs to be done to check the stones that are loose and potentially dangerous. Besides identifying the deterioration slope caused by weathering, erosion, cutting and blasting damage. Instead of probing failure that will occur, the emergence of crack can be an early sign of failure and it is important to monitor the cracks occurring. This can be done by recording the number and width of cracks at regular time intervals. This is suitable for low hazard potential failure [10].

\subsection{Unmanned Aerial Vehicle (UAV)}

An unmanned aerial vehicle (UAV) is a type of aircraft thatis operated without a human pilot on board. This current technology is widely applied in various fields to facilitate work. In the construction industry, UAV use for monitoring the construction site, construction inspection, thermography, infrared, photogrammetry, transport applications and marketing activities [11]. The most obvious application of UAV camera to produce aerial photography for the project using an airplane or helicopter conventionally has led to high expenses. However, replacing the conventional method with the UAVs will be able to provide high-quality video images at lower cost [12]. Image of aerial photographs taken in accordance with the characteristics of the flight path is straight and parallel. Images are taken at a certain time of intervals so that the area covered by each image along the flight path contains most of the photo image area covered by the previous image.

\section{Methodology}

Figure 1 shows the flowchart of the procedure of the method to obtain the slope visual information by using Unmanned Aerial Vehicle (UAV).

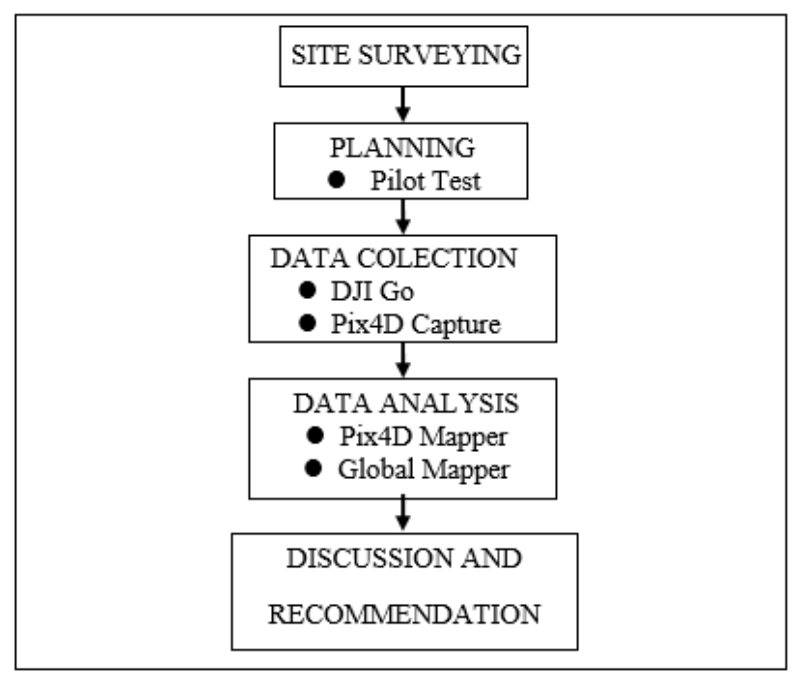

Figure 1. Flowchart of the procedure of the method to obtain the slope visual information

\subsection{Site Survey}

In this study, the chosen location was at Taman Harmoni Vista, at Jalan Panchor, Pagoh. Slope within 150 meters in length and 20 meters in height located at $2.15141808^{\circ}$ latitude, $102.72160858^{\circ}$ longitude and 63.318 meters altitude as a case study location as shown in Figure 2. From the information given by Sime Darby Officer, a school has planned to build on the high ground of the slope. As a school it will be built there, the slope alongside must be monitored.

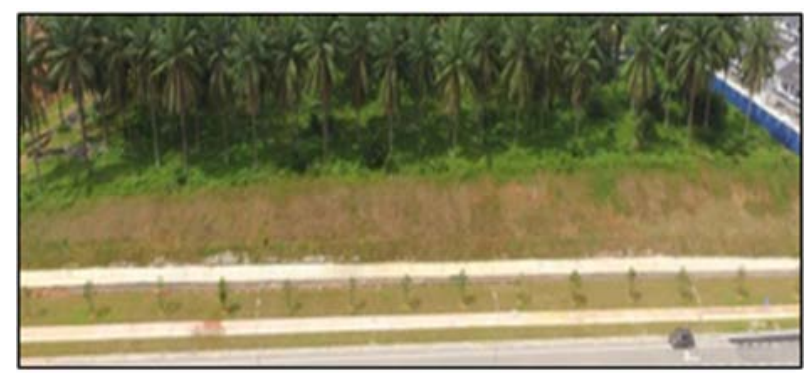

Figure 2. Study Area

The slope area is also near to the main road as shown in map in figure 3 . Thus, the slope is the best location to run this study because hazardous symptoms on the slope failure can be detected earlier and prevention steps can be taken in order to avoid any slope failure to happen and enhance the safety of the location. 


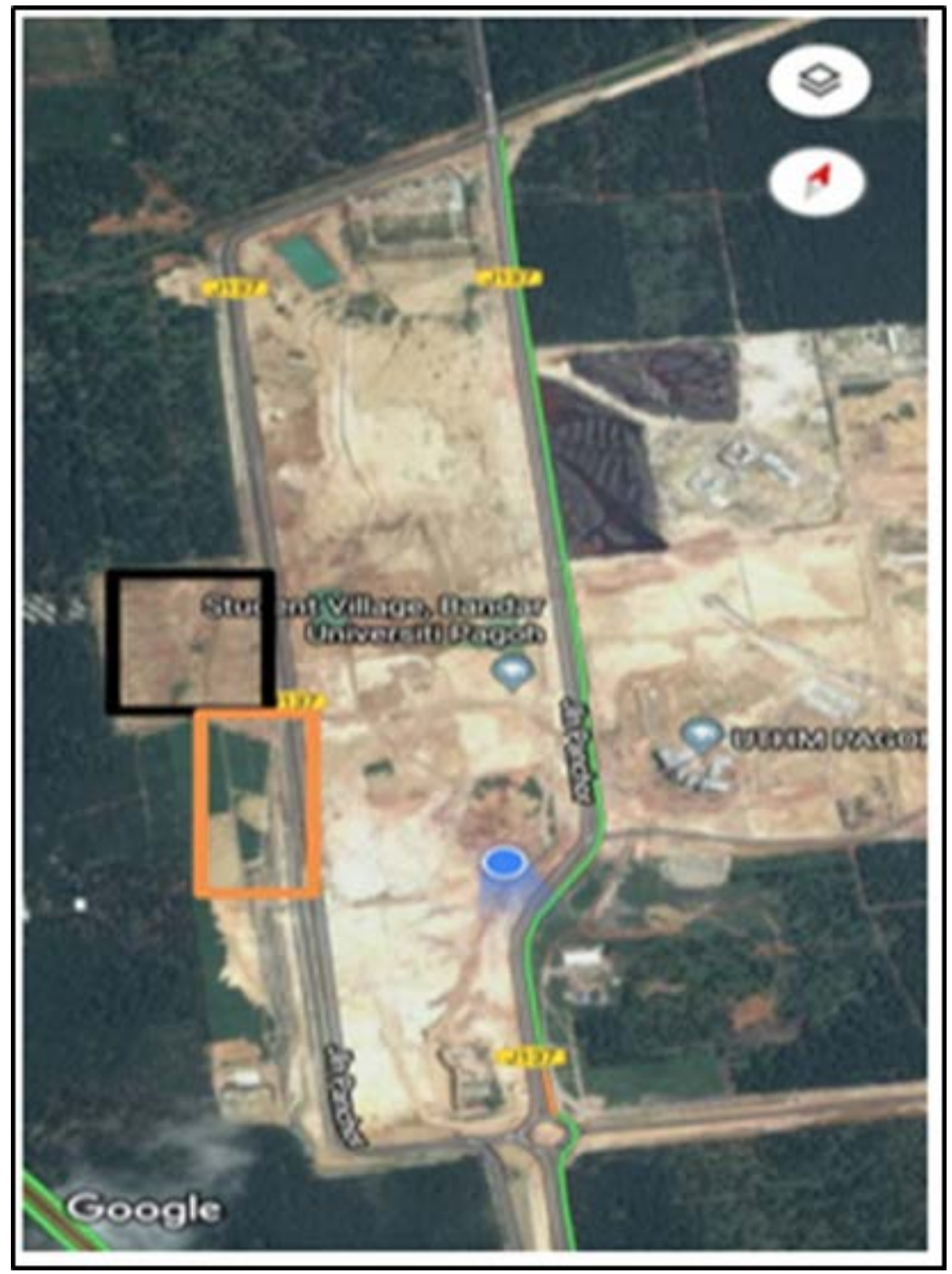

Figure 3. Slope's location on map

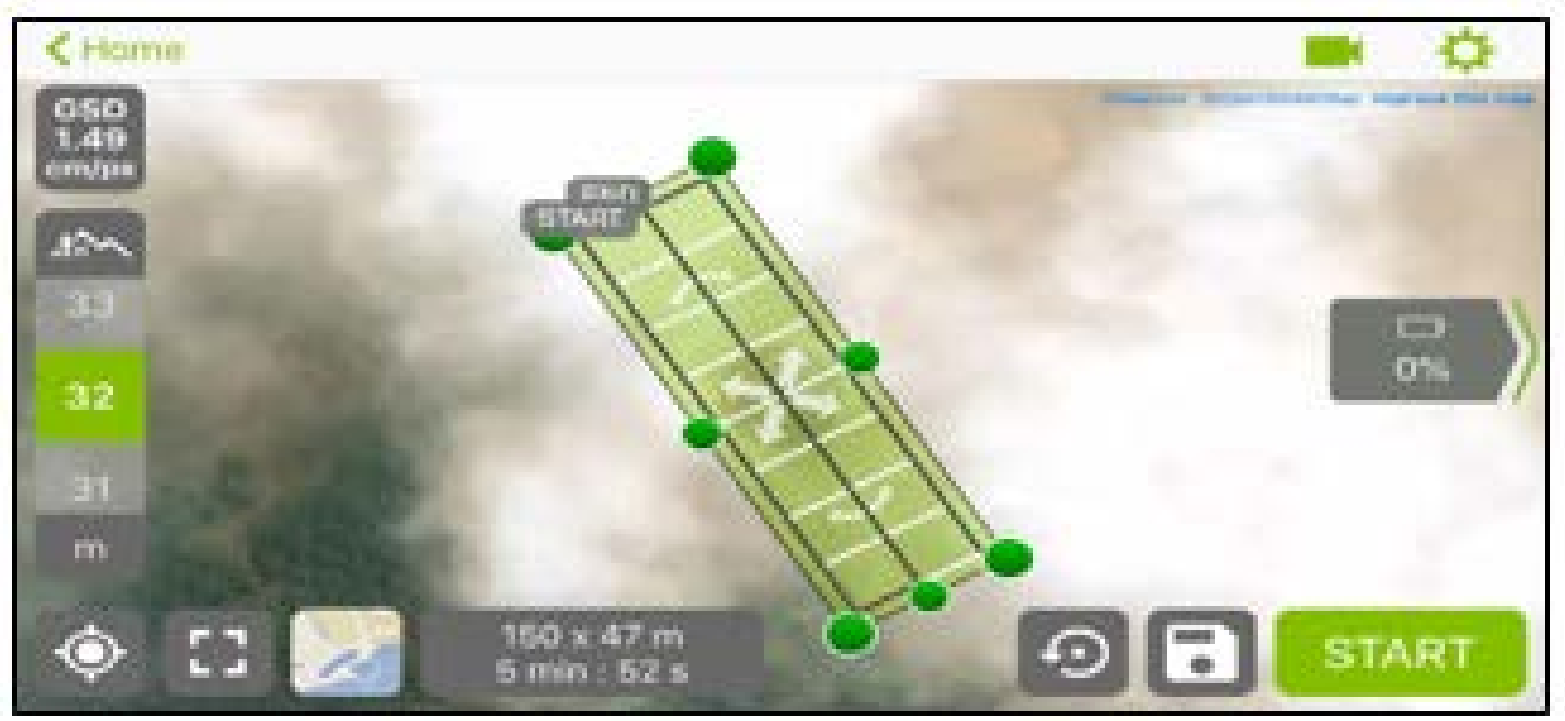

Figure 4. Parameters the flight plan and size mission 


\subsection{Data Collection and Processing}

In the planning process of this project, pilot test has been done for data accuracy and to ensure the flight safety. Checking weather condition is a must to get the better visual images and very critical not to fly drone in bad weather conditions especially during rainy days. Next, the drone's details planning using Pix4D Capture must be set as return home location and need to set correctly to ensure the safety return of UAV. Moreover, the parameters of flight plan and size mission must be set before launching the drone as shown in Figure 4. In this project, flight plan and size mission were using double grid to build a 3D model and 32 meters for the flight drone altitude. This pilot test is very important in order to avoid any problem occurring during the flight mission for actual data collection.

There were two applications that had been used for the data collection which were Dji Go and Pix4Dcapture. The flight plan for the study area was set within the Pix4D Capture with frontal overlapping of $75 \%$, side overlapping of $65 \%$ and the angle of camera of $70^{\circ}$. [13]. The flight was carried out at three different periods of time as shown in Table 1.

Table 1. Dates of flight

\begin{tabular}{|c|c|}
\hline Period & Flight date \\
\hline 1 & 18 October 2018 \\
\hline 2 & 18 November 2018 \\
\hline 3 & 7 December 2018 \\
\hline
\end{tabular}

All the visual images collected from the UAV were saved in the UAV's storage. The pictures were transferred into the computer and were generated using Pix4D Mapper and Global Mapper software to build slope's 3D modelling and get the visual image of the slope. Then, the 3D model was analyzed to identify the possibility of slope failure symptoms.

\section{Results and Discussion}

In the study, three flight missions with a UAV were carried out to monitor the slope. An average of 90 images was taken for each flight to generate the 3D models using pix4D Mapper software. From the 3D models, the slope studied can be analyzed to find the signs or symptoms of failure based on Jabatan Kerja Raya (JKR) slope maintenance standard guide. The slope is categorized as vegetated surface cover [14]. Table 2 shows the JKR slope maintenance standard guide is compared with the studied slope.

Table 2. Comparison of slope studied

\begin{tabular}{|c|c|c|c|}
\hline \multirow{2}{*}{$\begin{array}{c}\text { JKR slope maintenance } \\
\text { standard guide }\end{array}$} & \multicolumn{3}{|c|}{ Studied slope analysis } \\
\cline { 2 - 4 } & Perieod 1 & Perieod 2 & Perieod 3 \\
\hline Huge Rock(Boulder) & Absent & Absent & Absent \\
\hline Land movement & Absent & Absent & Absent \\
\hline Tension cracks & Absent & Absent & Absent \\
\hline $\begin{array}{c}\text { Surface crack on } \\
\text { drainage }\end{array}$ & Absent & Absent & Absent \\
\hline
\end{tabular}

\subsection{Boulder}

Based on the image analysis, boulder was absent in period 1, 2 and 3 because the slope is vegetated surface covered as shown in Figure 5. There is sufficient sunlight to support vegetation growth in the study area. Many failures in rock slopes involve minor rock falls. The presence of unstable upslope boulders which could impact on the boulder, particularly for those that are already overhanging or resting on other boulders where the contact is open or soil-filled or dipping out of the slope [14].

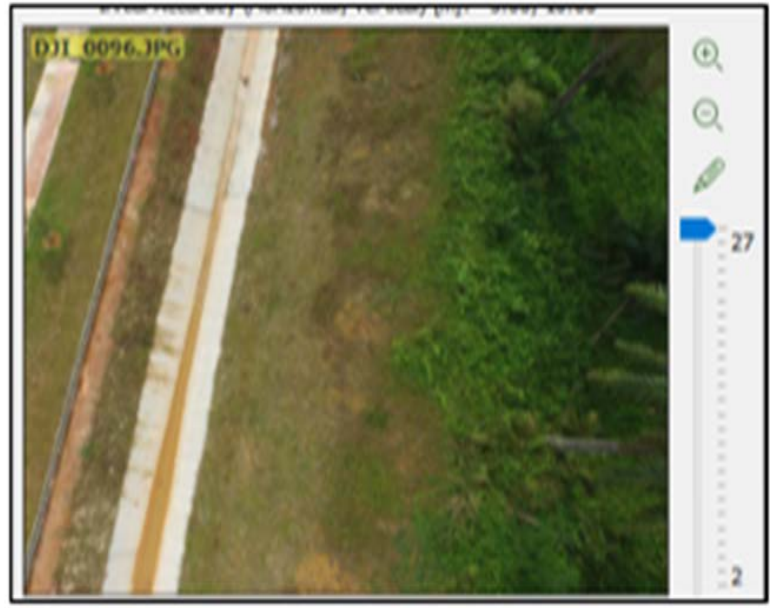

Figure 5. Vegetated surface covered

\subsection{Land Movement}

The contour analysis result from Global Mapper software did not show any deflection as shown in Figure 6. This indicates no sign of land movement during the observation period. The slope movement sign will show as an elevation difference in the contour analysis within the observation time. 


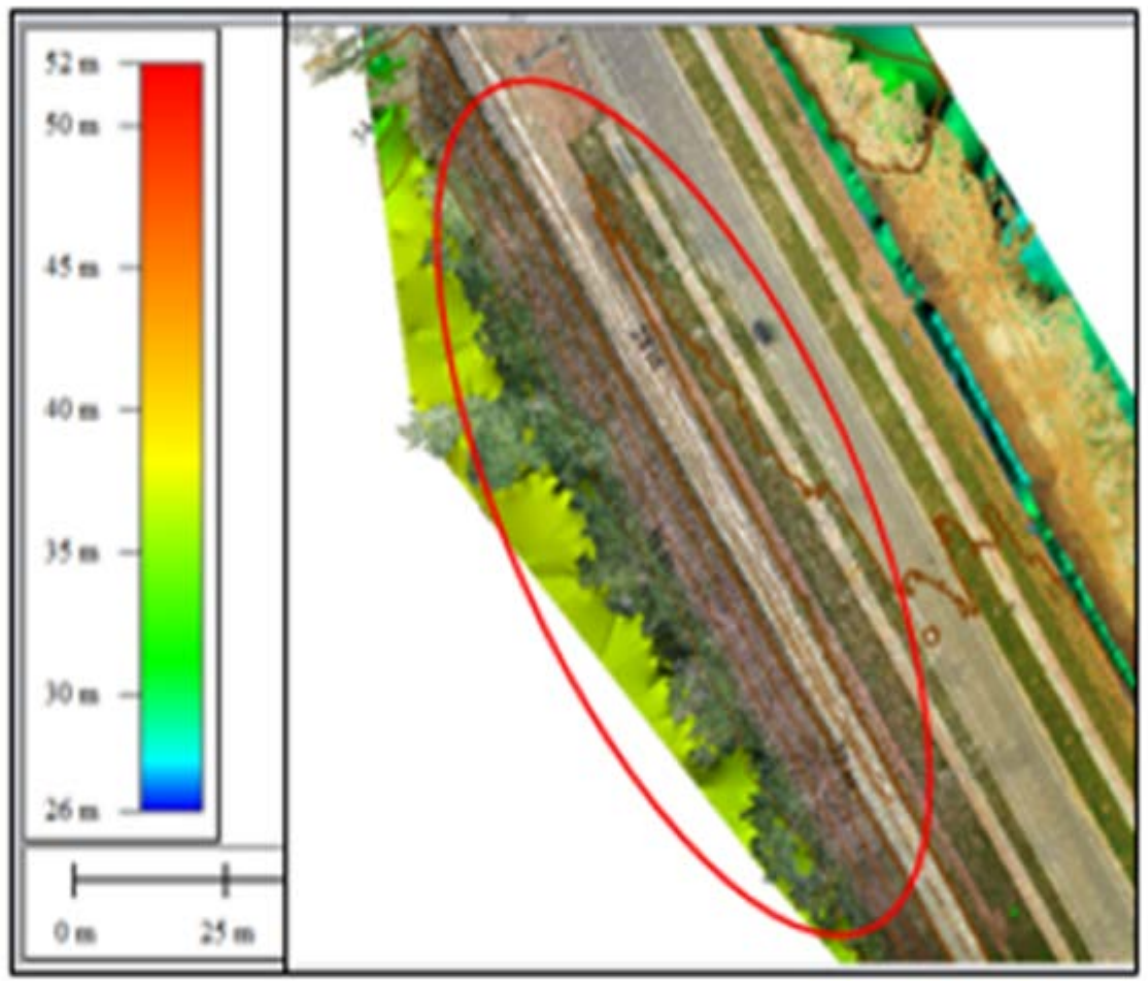

Figure 6. Contour in Global Mapper software

\subsection{Tension Cracks}

Tension cracks of slope occurred in period 1, 2 and 3 in displaying calibrated camera in initial position (m) 246612.86, 237946.76, 48.1. The length of the tension crack was about 1.5 meter as shown in Figure 7. Tension crack tends to form near the top of the slope as the condition of limiting equilibrium and failure to develop. A tension crack may develop in a slope when the inclination angle of the slip surface is steep and when the sliding mass is sitting on a weak foundation material. The typical maintenance work required is to repair the cracks or spalling. Cracked impermeable surface cover should be repaired by cutting a chase along the line of the crack, which is to be filled with similar slope cover material or flexible sealant.

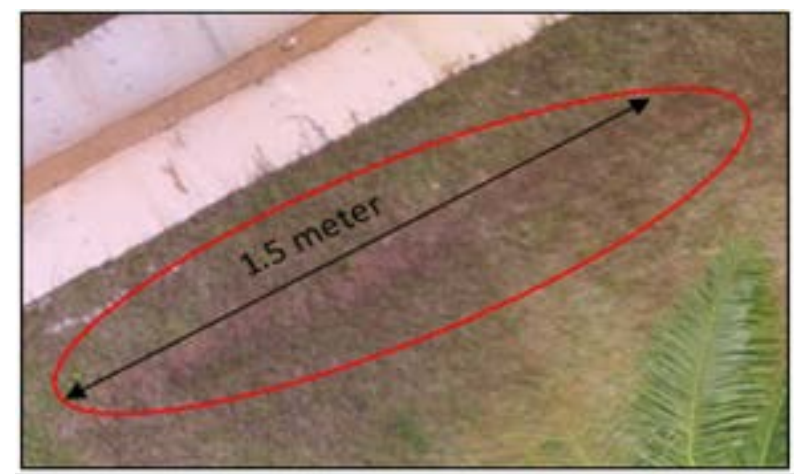

Figure 7. Tension crack of the slope

\subsection{Surface Cracks on Drainage}

The finding indicates surface cracks on drainage only occur in period 3. Figure 8 shows lateral crack on surface drainage occurs in period 3. Longitudinal cracks and lateral cracks originate at a certain point. Based on the analysis, the lateral crack was found in displaying calibrated camera in initial position (m) that is 246602.07, 237969.16, 49.2. Maintenance work is required to repair minor crack in order to prevent further crack. This minor crack can be fixed using cement mortar or flexible sealing compound. Furthermore, clearance works are also needed outside of site boundaries to prevent debris from blocking the drainage system.

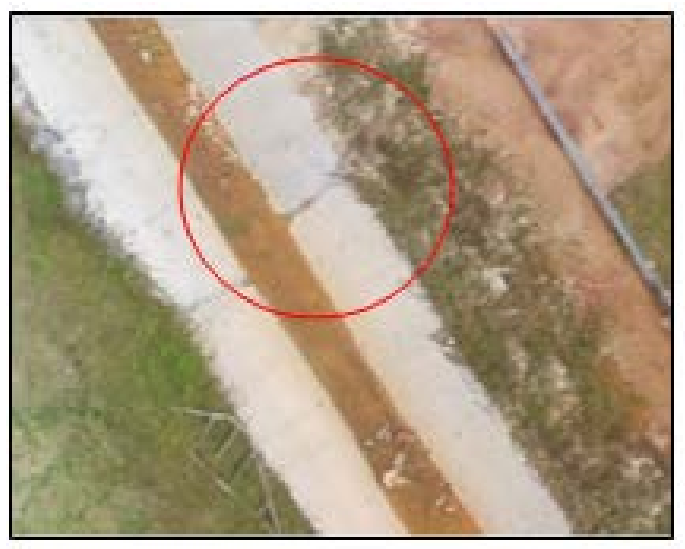

Figure 8. Lateral crack on surface drainage 


\section{Conclusions}

Currently, the UAV usage is in line with the changes of the nowadays technologies to make the inspection and monitoring work easier. This study introduces UAV as an alternative way to obtain data in the form of accurate images, 3D modelling of the slope to facilitate the slope monitoring process. Inspection used by Unmanned Aerial Vehicle (UAV) is able to obtain clearer and more accurate visual images. Every slope whether high risk slope or normal slope should be monitored regularly to identify any initial defects or damages. Therefore, if any defects or problems occur, any action may be taken and remedied detected earlier based on visual images and slope 3D modelling. Application of UAVs is a more flexible, fast and effective method for the acquisition of taking the visual data

\section{Acknowledgements}

The authors would like to express our deepest gratitude to all parties who have contributed to this research, especially to Tier 1 Grant (Vote H123), Pejabat Pendaftar UTHM, Office for Re-search, Innovation, Commercialization and Consultancy Man-agement, (ORICC), Center for Diploma Studies (CeDS), Sime Darby Property, Bandar Universiti Pagoh.

\section{REFERENCES}

[1] Komoo, I., Aziz, S., \& Sian, L. C. (2011). Incorporating the Hyogo Framework for Action into landslide disaster risk reduction in Malaysia. Bulletin of the Geological Society of Malaysia, 57(57), 7-11.

[2] Braathen A., Blikra L. H., Berg S. S. and Karslen F. (2004) "Rock-slope failures in Norway; type, geometry, deformation mechanisms and stability," Norwegian Journal of Geology, 67-88.

[3] Hunt R. E. (2005). Geotechnical Engineering Investigation Handbook, United States of America: CRC Press.

[4] Giordan, D., Manconi, A., Tannant, D. D., \& Allasia, P. (2015). UAV: Low-cost remote sensing for high-resolution investigation of landslides. International Geoscience and Remote Sensing Symposium (IGARSS), 5344-5347.

[5] Omar, M., Pichan, S., Rosli, M. (2015). A Detailed Investigation on Slope Failures at Federal Road (FT185) The Impending Improvement to JKR's Existing Guidelines For Road in Hilly Terrain. International Conference on Slopes. Kuala Lumpur, Malaysia: Slope Engineering Branch, JKR, 23-37.

[6] Utusan Online. (2016, January). Mengawasi cerun 24 jam. Utusan Online, p. 1. Yong Peng.

[7] Chao, H., Cao, Y. and Chen, Y. (2010) "Autopilots for Small
Unmanned Aerial Vehicles: A Survey," International Journal of Control, Automation, and Systems, 36-44.

[8] Ali, P. D. N. (2018). Slope Monitoring and Engineering Concept: Slope Recovery Course, Skudai: Universiti Teknologi Malaysia (UTM).

[9] Cawood, F. T., \& Stacey, T. R. (2006). Survey and Geotechnical Slope Monitoring Considerations. Journal of the Southern African Institute of Mining and Metallurgy, 106(7), 495-501.

[10] SIG-EHS-GU013. (2013). Slope stability guidelines sig-ehs-gu013, 36.

[11] Rok Cajezk, Gic Dradnje D.O.O, D. U. K. (2016). An Unmanned Aerial Vehicle for Multi-Purpose Task in Construction Industry, 11, 314-327.

[12] Opfer, N. D., \& P.E, D. R. S. (2014). Unmanned Aerial Vehicle Applications and Issues for Construction.

[13] Madawalagama S., (2019). Introduction to Photogrammetry. [Art]. Geoi formatics Center Asian Institute of Technology Thailand. https://www.itu.int/en/ITU-D/Regional-Presence /AsiaPacific/SiteAssets/Pages/Events/2018/Drones-in-agri culture/asptraining/B_introduction_to_photogrammetry1.p df

[14] Jabatan Kerja Raya (JKR), Guidelines on Slope Maintenance in Malaysia, Kuala Lumpur: Slope Engineering Branch Public Works Department Malaysia, 2006. 